\title{
O descanso dos naturalistas: uma análise de cenas na iconografia oitocentista
}

\author{
Naturalists at rest: an analysis of scenes \\ from nineteenth century iconography
}

\author{
Anderson Pereira \\ Antunes \\ Doutorando, Programa de Pós- \\ graduação em História das Ciências \\ e da Saúde/Casa de Oswaldo Cruz/ \\ Fiocruz. \\ Av. Brasil, 4036, sala 420 \\ 21040-361 - Rio de Janeiro - RJ \\ - Brasil \\ anderson.p.antunes@gmail.com
}

\section{Ildeu de Castro Moreira}

Professor, Instituto de Física/ Universidade Federal do Rio de Janeiro.

Av. Athos da Silveira Ramos, 149 Cidade Universitária

21941-590 - Rio de Janeiro - RJ - Brasil

ildeucastro@gmail.com

\section{Luisa Medeiros \\ Massarani}

Pesquisadora, Museu da Vida/Casa de Oswaldo Cruz/Fiocruz.

Av. Brasil, 4365

21040-900 - Rio de Janeiro - RJ

- Brasil

lumassa@fiocruz.br
ANTUNES, Anderson Pereira; MOREIRA, Ildeu de Castro; MASSARANI, Luisa Medeiros. O descanso dos naturalistas: uma análise de cenas na iconografia oitocentista. História, Ciências, Saúde - Manguinhos, Rio de Janeiro, v.22, n.3, jul.-set. 2015, p.1051-1066.

Resumo

Durante o século XIX, expedições científicas percorreram o Brasil investigando fauna, flora e natureza geológica. Com base em cartas, relatórios, livros de viagens e ilustrações, é possível retratar essas expedições, os naturalistas e os auxiliares que os acompanhavam, assim como a sociedade oitocentista brasileira. Nosso foco é a iconografia dos viajantes. As imagens dão subsídios para compreendermos o olhar do naturalista viajante sobre a natureza, os homens do interior e as populações indígenas. A partir da comparação de oito imagens, selecionadas pelo fato de ilustrarem os acampamentos dos viajantes, buscamos observar suas semelhanças e diferenças, desvelando o que elas nos dizem a respeito desses viajantes, suas expedições e o contexto em que atuaram.

Palavras-chave: naturalistas viajantes; Brasil; século XIX; expedições científicas; iconografia.

\begin{abstract}
During the nineteenth century, scientific expeditions travelled across Brazil investigating its fauna, flora and natural geological resources. By examining letters, reports, travelogues and illustrations of that time, it is possible to picture those expeditions, the naturalists themselves and the assistants who accompanied them, as well as something of society in nineteenth century Brazil. Our research focuses on the iconography of these travelers. These images help us to understand the way these traveling naturalists viewed nature, the men living in the interior and the indigenous peoples. By comparing eight images selected to illustrate the travelers' campsites we sought to observe their similarities and differences, revealing what they tell us about these travelers, their expeditions and the context in which they worked.
\end{abstract}

Keywords: traveling naturalists; Brazil; nineteenth century; scientific expeditions; iconography. 
$P^{3}$ ara a ciência, o século XIX foi um período de grandes transformações, formulações teóricas e muitas inovações no campo de suas aplicações. Surgiu também maior interesse do Estado pela ciência, uma vez que ela carregava consigo as promessas de progresso tecnológico e de avanços econômicos. Financiar a atividade científica tornou-se uma ação deliberada dos principais governantes europeus, e as expedições científicas de reconhecimento e exploração passaram a figurar no topo de suas agendas, pois possibilitavam a realização de consideráveis levantamentos dos recursos naturais disponíveis, que tinham valor científico e econômico. No contexto mais amplo da expansão colonial, as expedições ainda cumpriam objetivos políticos e militares relacionados com o mapeamento e o domínio de terras não exploradas pelos países europeus.

Assim, os mares do Atlântico e do Pacífico se viram cada vez mais frequentados por navios que levavam naturalistas e seus auxiliares em direção às terras do Novo Mundo. Inspirados e incentivados por aqueles que já se haviam aventurado, cada vez mais naturalistas partiam em viagens transatlânticas. Essas viagens se tornaram verdadeiros "ritos de passagem para aqueles que almejavam a consolidação de suas carreiras" (Lopes, 2009, p.52). Um dos maiores proponentes da ciência viajante foi o naturalista Friedrich Heinrich Alexander, barão de Humboldt (1769-1859), que compreendia a viagem como uma etapa fundamental para o estudo da natureza, afirmando: "Quando o homem interroga a natureza com sua curiosidade penetrante ou mede, em sua imaginação, os vastos espaços da criação orgânica, de todas as emoções que experimentará, a mais poderosa e mais profunda é o sentimento de plenitude da vida universalmente espalhada" (Humboldt, 1850, p.212). ${ }^{1}$

A grande quantidade de viagens levou à publicação de enciclopédias dedicadas inteiramente a compilar as empreitadas dos viajantes. Em 1833, por exemplo, Albert Montémont (1788-1861) publicou uma enciclopédia intitulada Bibliothèque universelle des voyages..., em que afirmava:

As viagens são a escola do homem, ele não dá um passo sem aumentar os seus conhecimentos e ver diante de si recuar o horizonte. À medida que avança, seja mediante observações próprias, seja lendo os relatos de outros, ele perde um preconceito, desenvolve seu espírito, apura seu gosto, engrandece sua razão, acostuma-se ao altruísmo. $\mathrm{E}$, tanto por vontade quanto por justiça em relação à humanidade, sente-se inclinado a tornar-se cada dia melhor, dizendo-se a si mesmo, segundo o filósofo inglês Tolland: o mundo é a minha pátria, e os homens, meus irmãos (Montémont, 1833, p.1).

O Brasil logo se destacou como destino dos viajantes, não apenas por suas riquezas naturais, mas por ter sido um dos últimos locais a mostrar-se disponível, uma vez que, desde a chegada dos portugueses e até 1808, as políticas protecionistas de Portugal procuravam manter os viajantes estrangeiros afastados. Após a chegada da família real portuguesa e da abertura dos portos às nações amigas, as terras brasileiras começaram a ver o recuo das políticas isolacionistas que antes resguardavam seu território.

Os viajantes que aqui aportavam relatavam suas viagens em relatórios científicos, em cartas que enviavam aos seus correspondentes e em diários e livros de viagens que eram posteriormente publicados na Europa. Essas publicações eram geralmente ilustradas por gravuras, algumas feitas a partir de esboços que os próprios naturalistas realizavam in loco, outras de autoria dos artistas que contratavam para acompanhá-los. Os relatos logo ganharam popularidade entre o público europeu, que, curioso e interessado pelas jornadas que os 
naturalistas haviam vivido, consumia avidamente a literatura de viagens. Com o aumento da demanda, esse tipo de publicação se tornou, também, um referencial de rendimentos para os viajantes, servindo como fonte alternativa para o financiamento de suas viagens e como forma de gerar visibilidade para o trabalho científico que haviam realizado (Leite, 1997).

Texto e imagem eram dois meios complementares de registrar não apenas os espécimes e os cenários observados, mas também as sensações e emoções experimentadas pelos naturalistas diante daqueles contextos. Segundo postulava Humboldt, as sensações estéticas e as experiências vividas pelos viajantes em suas viagens de exploração também faziam parte do arcabouço essencial à formação de conhecimento científico. Com as imagens, os naturalistas tentavam dar conta de exprimir motivos que seriam intraduzíveis apenas com palavras. Segundo afirma Kury (2001, p.870):

Para grande parte dos naturalistas do século XIX, a multiplicidade de sensações que envolvem o naturalista em sua viagem poderia e deveria ser descrita pela ciência. Daí o uso de representações pictóricas e a preocupação com os recursos literários das narrativas de viagem. Assim, o cientista que se fez viajante escolheu não apenas ver com os próprios olhos, mas ouvir e sentir com o próprio corpo os fenômenos lá onde acontecem.

Em seus relatos textuais e visuais, podemos encontrar, em alguns casos, valores ambivalentes em algumas dessas descrições: de um lado, alguns viajantes não pouparam palavras ou traços de seus pincéis para retratar uma visão idealizada da "terra prometida", associando a natureza tropical aos jardins do Gênese; de outro, também é possível encontrar viajantes que exageraram seus relatos no sentido oposto, criando um cenário no qual florestas impenetráveis estavam eivadas de animais peçonhentos e de selvagens perigosos.

Embora seja difícil medir as proporções de observação e imaginação que os viajantes colocaram em seus relatos, é impossível negar a importância de seu legado científico e iconográfico. Os livros de viagem tiveram um papel importante na atração de jovens para a atividade científica e representaram um verdadeiro domínio literário de divulgação científica. Em anos recentes, o acervo formado pelos registros dos viajantes naturalistas tem se tornado, cada vez mais, fonte de pesquisa para os historiadores. A partir de seus livros e ilustrações podemos analisar não apenas a ciência do século XIX e seus viajantes, mas também os locais por eles visitados, seus habitantes e costumes, além das visões subjacentes nas quais estavam escorados. No entanto, as pesquisas realizadas geralmente limitam seu escopo aos relatos textuais, e as imagens são, em muitos casos, utilizadas de forma apenas ilustrativa. Com esta investigação, pretendemos destacar a importância de, em certo sentido, inverter essa tendência e tomar os registros iconográficos como fontes primárias de análise.

O primeiro passo deste estudo foi examinar alguns livros de viagens publicados pelos naturalistas que percorreram o Brasil, atualmente disponíveis on-line no acervo de grandes bibliotecas virtuais, como a Biblioteca Nacional do Brasil, a Gallica ou o Internet Archive. A primeira etapa para a seleção das imagens, em meio digital, seguiu três critérios: temporal, delimitando nossa pesquisa à produção realizada durante o século XIX; geográfico, referindo-se apenas às imagens feitas no Brasil ou que retratassem o país; e temática, na qual nos restringimos às imagens que apresentassem os viajantes ou seus auxiliares em cenas de acampamento.

O trabalho analítico, por sua vez, deu-se em cinco etapas (Antunes, 2012). Na primeira, relacionada com os dados biográficos do autor, levantamos algumas das principais informações 
sobre o naturalista e/ou artista responsável pela imagem. Em seguida, analisamos os dados históricos acerca da imagem selecionada, situando-a na biografia de seu autor e da expedição que representa. Com autor e obra situados no tempo e no espaço, partimos para um estudo do tema, etapa que envolveu a descrição da imagem e sua comparação com o relato do naturalista sobre a cena. Realizamos, também, um estudo da forma, etapa que nos permitiu analisar os dados físicos da obra, como material, técnica e suporte utilizados por seu autor. Por fim, a última fase de estudo foi comparativa, na qual diversos desses registros possibilitam enriquecer a análise, fornecendo uma visão mais ampla e diversificada sobre o tema. Para Panofsky (1979), a comparação entre um registro visual e outros registros pertencentes à mesma época é imprescindível para maior compreensão de seu significado.

Para as finalidades deste artigo, selecionamos oito imagens disponibilizadas on-line que retratassem locais de acampamento e repouso dos naturalistas e enfatizamos seu estudo do tema. O registro de cenas de acampamento aparece como tema constante em muitos dos relatos investigados. Vários foram os viajantes que ilustraram os cenários em que seu grupo acampava para descansar, revelando detalhes sobre os abrigos, a alimentação, os companheiros de viagem, as relações entre eles, seus meios de transporte e os espécimes de fauna e flora que os rodeavam. Por isso, optamos por analisar imagens sobre tais acampamentos, visando entender o que elas pretendem expressar e o que nos dizem sobre os locais de pouso e descanso de alguns desses viajantes que percorreram o Brasil durante o século XIX.

A escolha dos relatos de viagens aqui investigados levou em conta o significado científico das expedições, a diversidade de seus componentes, em geral naturalistas e artistas estrangeiros ou brasileiros de destaque, e das regiões do país em que ocorreram. Assim, consideramos a Comissão Científica do Império (1859-1861), da qual participou o artista José dos Reis Carvalho (1798/1800-1892?); a viagem realizada pelo artista Jean-Baptiste Debret (1768-1848) entre 1816 e 1831; e a excursão do engenheiro Franz Keller-Leuzinger (1835-1890) com seu pai e seu irmão, feita entre 1867 e 1873 . Levamos em conta ainda os relatos dos naturalistas Alfred Russel Wallace (1823-1913), que esteve na região amazônica entre 1848 e 1852; Henry Walter Bates (1825-1892), que viveu na região amazônica durante 11 anos, entre 1848 e 1859; Alcide D’Orbigny (1802-1857), que de 1826 a 1833 percorreu diversos países da América do Sul; e Carl Friedrich von Martius (1794-1868) e Johann Baptiste von Spix (1781-1826), que estiveram juntos no Brasil entre 1817 e 1820.

\section{Analisando um registro da Comissão Científica do Império}

Para iniciar nossa análise, selecionamos uma obra do pintor brasileiro José dos Reis Carvalho (Figura 1), que acompanhou a Comissão Científica do Império em sua viagem de exploração ao Nordeste (Kury, 2009). Cruzando as informações que temos sobre sua datação (1859, assinalado pelo artista no canto inferior direito) e o itinerário da expedição, essa cena possivelmente teve lugar nas redondezas de Santa Rosa, entre Aracati e Icó, no Ceará. Como artista associado à expedição, a tarefa de Reis Carvalho era a de registrar aquilo que ele e seus colegas encontravam no trajeto, incluindo não apenas ilustrações zoológicas e botânicas, mas paisagens, edificações, habitantes locais e, também, as condições de viagem de seu grupo. 
Em sua obra, podemos ver a cena de um acampamento em meio à natureza. Em primeiro plano, observamos dois homens sentados em caixotes, segurando cachimbos e conversando, fazendo uma refeição. Ambos estão trajando roupas que cobrem seu corpo por completo, com calças, camisas de mangas compridas, botas e chapéus. Enquanto um deles apresentase virado de costas para o espectador, o outro, que carrega uma bolsa vermelha no ombro, parece encarar seu retratista. Em um caixote à esquerda, há duas inscrições: "CS", indicando o pertencimento daquele material à Comissão Scientifica, e "Secção Zoológica". Suas vestimentas, ações e seu lugar de representação em meio à composição são evidências de que os dois personagens possuem posições de elevada hierarquia social dentro do grupo, devendo tratar-se, portanto, de dois naturalistas. A partir da última inscrição, podemos ir além e supor que o personagem de maior destaque ao centro da composição é Manoel Ferreira Lagos, que foi quem atuou como chefe da seção zoológica.

Logo atrás da dupla, uma grande árvore, pintada em fortes tons de marrom e verde, com uma rede estendida na cor branca, com bolas vermelhas, divide a composição ao meio. À esquerda, podemos observar um grupo formado por quatro homens, sendo três deles representados com vestimentas mais simples e descalços, e um quarto, trajando uma espécie de farda em azul e vermelho, o que nos leva a crer que provavelmente se tratava de um oficial atuando na segurança do grupo de viajantes. Os quatro, no entanto, reúnem-se em uma tarefa em comum: cuidar dos cavalos que serviam como meio de transporte para o grupo. A variedade de ações que praticam nos dá ideia da rotina de cuidado com esses animais em uma viagem pelo interior como aquela.

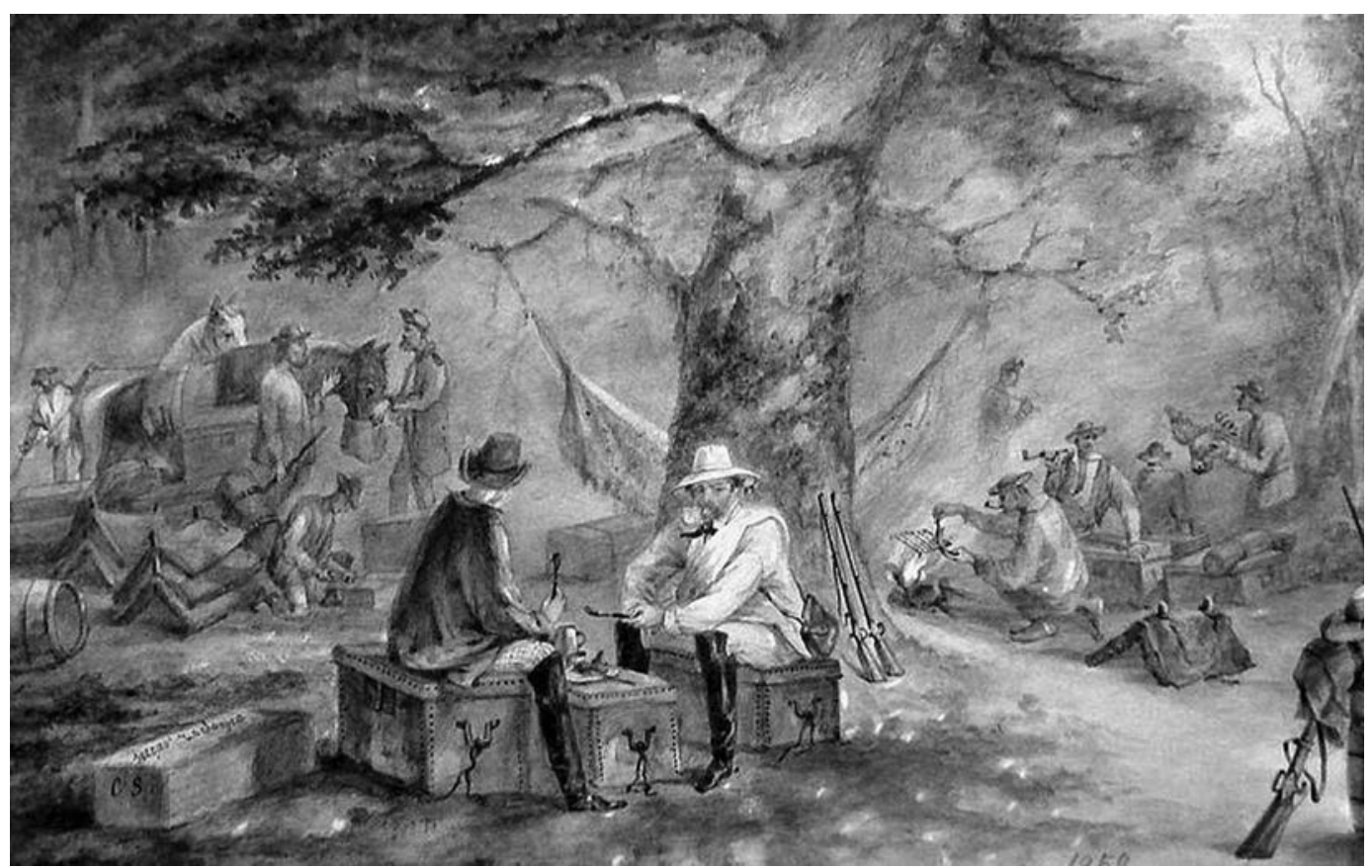

Figura 1: José dos Reis Carvalho [registro de cena da Comissão Científica do Império], 1859

(Fonte: http://commons.wikimedia.org/wiki/File:Jos\%C3\%A9_dos_Reis_Carvalho_-_Sem_t\%C3\%ADtulo,_1859.JPG). 
Do lado oposto, há outro grupo, formado por cinco indivíduos. Novamente, vemos um oficial fardado em azul, que se encontra mais ao fundo, como se patrulhasse a região. À frente, veem-se quatro homens. Enquanto dois deles estão sentados em caixotes, outros dois realizam tarefas distintas. Um deles, em pé, carrega em suas mãos uma ave, provavelmente abatida para compor a coleção de pássaros formada por Lagos e posteriormente depositada no Museu Nacional. O outro homem encontra-se ajoelhado em frente a uma fogueira, em que podemos vê-lo colocando um pequeno peixe sobre uma grade de metal. Além desses personagens, é possível observar, espalhados pela composição, vários caixotes, material de montaria, armas, vestimentas, todo tipo de material que o grupo carregaria consigo durante uma incursão pela natureza.

Outro viajante que retratou cenas de acampamento foi o alemão Franz Keller-Leuzinger, que veio ao Brasil em 1867, acompanhado de seu pai e de seu irmão. Contratada pelo ministro de Obras Públicas do Rio de Janeiro, a família Keller partiu para explorar as regiões cortadas pelos rios Amazonas e Madeira, a fim de realizar um estudo de viabilidade de construção de uma estrada de ferro na região. Durante a viagem, Keller-Leuzinger (1875) aproveitou-se de sua habilidade como desenhista para fazer uma série de 86 desenhos, dos quais selecionamos dois para análise.

Com o título de Parada sob um gigante da floresta primordial (Madeira) (Figura 2), a cena revela um acampamento provisório em meio à floresta, na qual os viajantes estão divididos em três grupos: em primeiro plano, observamos dois ajudantes. Enquanto um deles encontrase deitado, sobre uma das três pequenas embarcações utilizadas pelo grupo, o outro aparece ajoelhado junto a uma fogueira, preparando uma refeição em uma pequena panela de formato arredondado. Ao voltarmos nosso olhar para a imagem de Reis Carvalho, verificamos grande semelhança na representação do ajudante encarregado da fogueira.

Diferentemente de Reis Carvalho, Keller-Leuzinger apresenta os ajudantes em primeiro plano, enquanto outros três personagens, provavelmente ele próprio, seu pai e seu irmão, são mostrados ao fundo, envoltos pelas sombras das grandes árvores que os cercam. Os três engenheiros, assim como os naturalistas representados por Reis Carvalho, reúnem-se sentados ao redor de uma jarra para beber, descansar e, possivelmente, planejar o próximo trecho de sua viagem; já seus auxiliares fazem os serviços usuais de montagem ou manutenção do acampamento. No lugar de caixotes, o grupo de Keller-Leuzinger aparece mais bem preparado, com cadeiras e mesa dobráveis. Ainda mais ao fundo, podemos observar outro ajudante, afastado e de costas para o grupo, talvez em busca de algum animal que pudesse ser transformado em comida por seu companheiro encarregado da fogueira.

O cenário em que os personagens estão inseridos nas duas cenas apresenta algumas similaridades. Em ambos os casos, percebemos a presença de uma grande árvore criando um ponto focal na cena. Os artistas representam a flora de maneira a destacar sua riqueza, mostrando um ambiente de vegetação frondosa, que envolve os viajantes e que, em alguns casos, demonstra semelhanças com a "estética do sublime". Surgida na Europa durante o século XVIII, a expressão remete a uma corrente artística em que a natureza era retratada de forma grandiosa e extraordinária, em oposição às figuras humanas, inseridas em tamanho diminuto para demonstrar a pequenez do homem perante a natureza. 


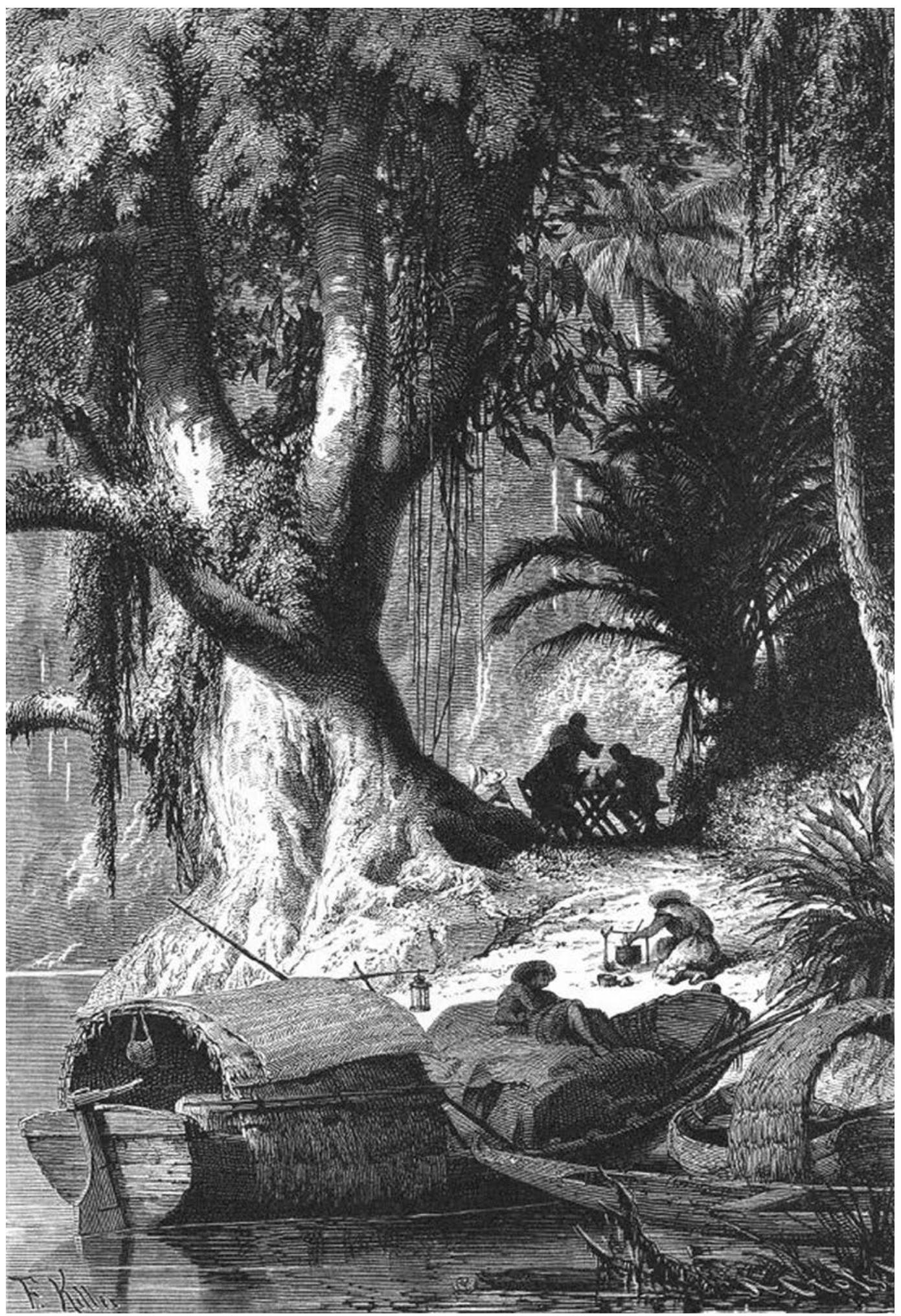

Figura 2: Franz Keller-Leuzinger, Parada sob um gigante da floresta primordial (Madeira), 1867 (Keller-Leuzinger, 1875) 
Na ilustração intitulada Nossa tenda sob as palmeiras, preparações para tomar a altitude do Sol (Madeira) (Figura 3), Keller-Leuzinger mostra um tipo diferente de acampamento. A presença dos ajudantes é ocultada, e apenas dois personagens são representados, em primeiro plano. Ao comparar os personagens com uma fotografia de Keller-Leuzinger de 1874, podemos supor, por seus traços faciais e sua barba, que o engenheiro é o personagem em pé, segurando o que pode ser um instrumento de medição da altura do Sol. A seu lado, possivelmente seu

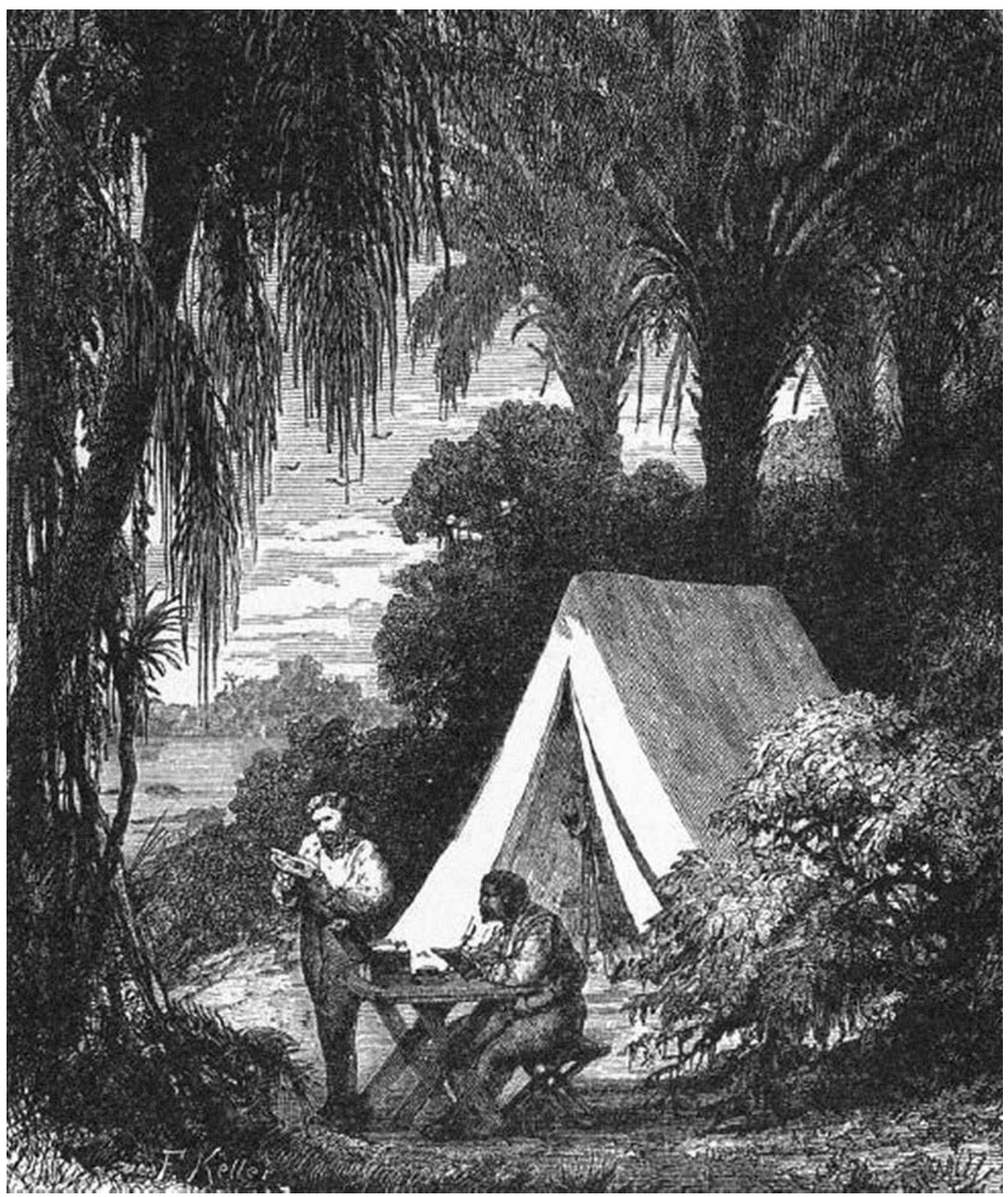

Figura 3: Franz Keller-Leuzinger, Nossa tenda sob as palmeiras, preparações para tomar a altitude do Sol (Madeira), 1867 (Keller-Leuzinger, 1875, p.110) 
pai aparece sentado, fazendo anotações em um caderno. Reunidos em volta de uma mesa de madeira, ambos parecem compenetrados em sua tarefa. Atrás dos viajantes, uma cabana triangular reserva o abrigo necessário para se passar a noite em meio à floresta.

A representação de acampamentos de viagem também foi tema para a dupla de viajantes formada por Martius e Spix. Convidados para compor uma missão artística e científica austroalemã, a dupla passou três anos explorando diversas regiões do território brasileiro, entre 1817 e 1820 (Spix, Martius, 1823-1831). A gravura Preparação para a escavação de ovos de tartaruga no Amazonas (Figura 4) foi realizada por Martius e representa uma cena de acampamento que tinha a finalidade de recolher ovos de tartaruga no período propício. Nela, observamos um grupo diversificado de pessoas, das quais podemos identificar, além dos viajantes europeus, escravos e indígenas. A presença de escravos nas expedições de exploração era bastante comum durante o século XIX. Os "negros naturalistas", como os chamou Debret, atuavam como guias e serviçais, além de ser frequentemente hábeis caçadores e coletores de espécimes. A presença dos indígenas é um tema recorrente em muitas dessas imagens de acampamentos, atestando o papel desempenhado por eles como auxiliares das expedições. Muitos foram os viajantes que souberam aproveitar a experiência das populações locais - indígenas ou não - e seu conhecimento das regiões visitadas, especialmente na Amazônia. Na gravura de Martius, podemos ver um indígena ao lado de um dos viajantes ao centro da composição. Armado com um rifle, o viajante aponta a arma na direção indicada pelo nativo. O cenário, por sua vez, é dividido entre a vegetação e a praia. A vegetação, novamente, recebe grande destaque, tomando conta da maior parte do cenário.

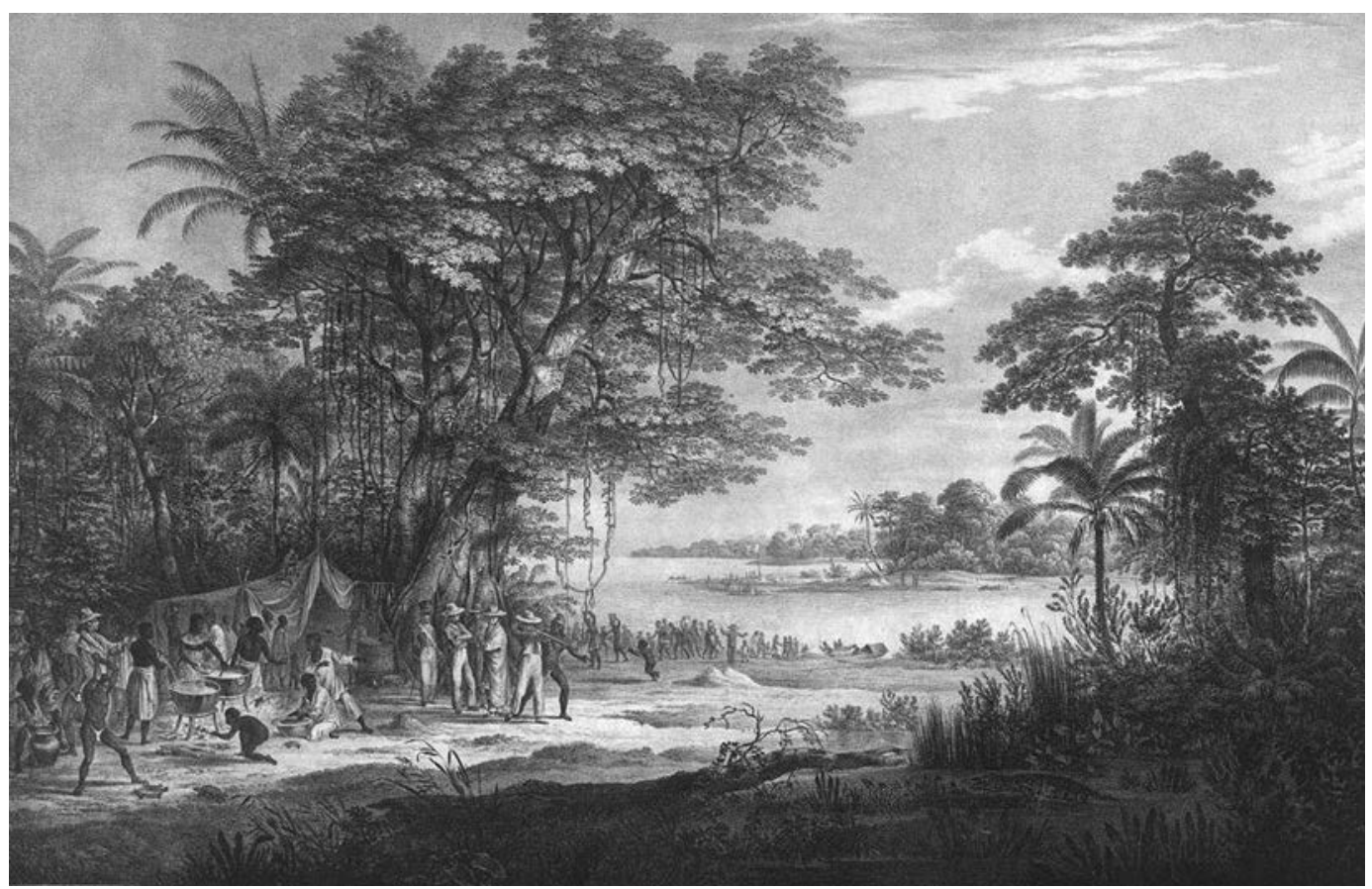

Figura 4: Carl Friedrich Philipp von Martius, Preparação para a escavação de ovos de tartaruga no Amazonas, 1823-1831 (Spix, Martius, 1823-1831, p.27) 
Em uma cena desenhada por Johann Baptist Zwecker (1814-1876) sobre a expedição de Henry Walter Bates, vemos uma situação semelhante à anterior, em que o grupo de viajantes acampa próximo a um rio (Figura 5). Em seu livro de viagens, Bates descreve suas excursões pela região de Ega (hoje Tefé) e relata a presença no acampamento de um "visitante indesejado".

Nessa cena, observamos o que Bates chama de "ranchos", estruturas circulares formadas por troncos de madeira erguidos verticalmente e cobertas de folhagem nas quais redes eram penduradas entre os troncos, para que os viajantes pudessem descansar protegidos dos perigos que rastejavam. No canto direito do rancho, sobre uma das redes, podemos ver o próprio Bates, com sua mão direita erguida para o alto enquanto tenta - com a ajuda de seu amigo e companheiro de viagem, o delegado de polícia de Antonio Cardoso, em pé e do lado oposto espantar o jacaré que se aproxima do acampamento. Logo atrás, há outros auxiliares de viagem, escondidos e amedrontados pela presença do grande réptil. Em seu livro de viagens, pode-se ler:

Cerca de meia dúzia de jacarés já adultos estavam à espera... A cada dia, esses visitantes tornavam-se mais ousados, alcançando uma imprudência que era bastante intolerável... Bem, certa noite eu fui acordado por um grande alvoroço. Fora causado por Cardozo balançando gravetos em chama enquanto praguejava em voz alta em direção a um enorme jacaré-de-papo-amarelo que havia rastejado margem acima e passado por debaixo de minha rede (estando ela mais próxima da água) e em direção ao lugar onde Carlito se deitava. O cachorro havia nos alarmado a tempo; o réptil recuou e rolou margem abaixo, as faíscas dos gravetos em chama jogados contra ele voavam de sua ossuda traseira (Bates, 1864, p.371).

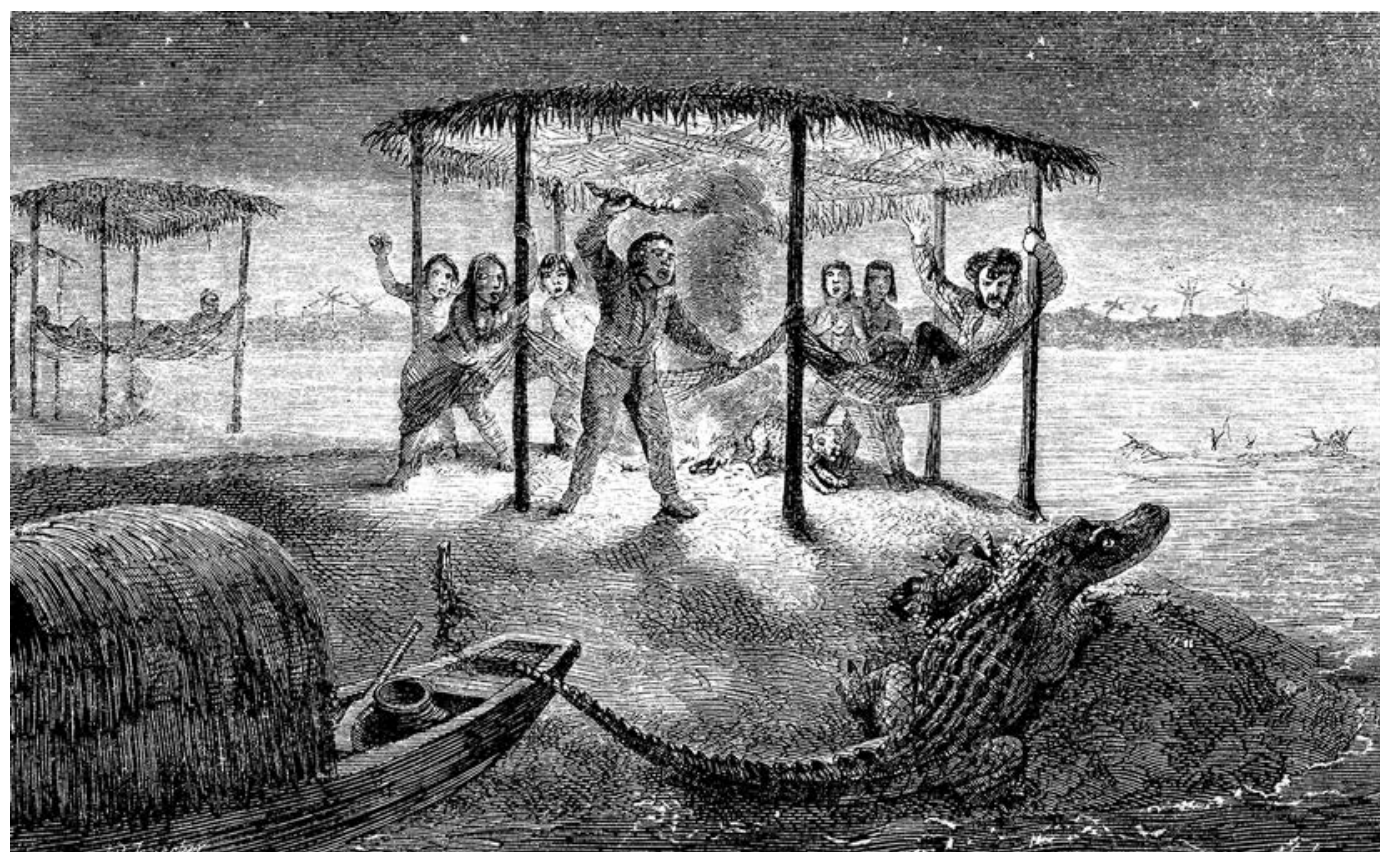

Figura 5: Johann Baptist Zwecker, Aventura noturna com jacaré, 1864 (Bates, 1864, p.370) 
Em oposição às imagens anteriores, o que podemos observar nessa imagem é que a estada dos viajantes pelo interior do país não era desprovida de perigos, embora eles fossem exagerados em muitos relatos. Uma vez que os livros de viagem se tornaram um verdadeiro gênero literário na Europa, com muitos leitores ávidos para consumir tais obras, era comum que os viajantes floreassem as narrativas de suas experiências, tentando garantir o interesse do leitor. A presença de um cachorro, servindo de guarda junto ao acampamento, não era incomum, é algo que podemos encontrar em algumas cenas de viagens semelhantes.

Junto com Bates, também veio ao Brasil o naturalista Alfred Wallace. Em Viagens pelos rios Amazonas e Negro (Wallace, 1979), encontramos uma passagem na qual o autor relata, em texto e imagem, a sua estada em Belém, na borda da floresta. Os acampamentos em meio à floresta ou à beira de rios não representavam a única opção para os viajantes que cruzaram o Brasil. Os locais para repouso ou residência temporária podiam variar de casas alugadas ou de conhecidos, nas regiões urbanas, a vendas, ranchos ou taperas no campo. Era comum que viajantes estrangeiros se comunicassem por cartas com conterrâneos que já estivessem instalados aqui e pedissem conselhos sobre lugares mais adequados para se hospedar.

Wallace e seu companheiro Bates alugaram, logo que chegaram a Belém, uma pequena casa, próximo à Capela de Nazaré, que serviu como base para seu trabalho inicial de coleta nas florestas dos arredores da cidade. A cena descreve um cenário muito diferente dos que vimos anteriormente, já que se situa dentro de um perímetro urbano, embora esteja nas proximidades de uma floresta com grande biodiversidade. Podemos observar duas fileiras de casas simples e, ao fundo, uma pequena capela, possivelmente a primeira retratação daquela construção que antecedeu a atual Basílica Santuário de Nossa Senhora de Nazaré. A casa em que residiam Wallace e Bates foi alugada por vinte mil-réis, do português Joaquim Francisco Danin; tinha quatro quartos e uma extensa varanda que a circundava. Segundo Wallace (1979, p.19), a localização era estratégica para suas expedições, pois "logo atrás dela começava a floresta, oferecendo excelentes locais para a coleta de pássaros, insetos e plantas".

Em primeiro plano (Figura 6), veem-se três personagens, sendo possível supor que poderiam ser o próprio Wallace, Bates e o também naturalista Richard Spruce (1817-1893), que se juntou à dupla em 1849. Outra possibilidade é que o terceiro personagem seja Herbert, irmão de Wallace que veio ao Brasil junto com Spruce. Da mesma forma como observamos nas imagens de Reis Carvalho e Keller-Leuzinger, os viajantes são representados juntos, enquanto conversam e descansam em um final de tarde. Em The naturalist on the river Amazons, Bates (1864) descreveu a rotina cotidiana do trabalho naturalista. Após as atividades na mata, que começavam com o alvorecer do dia, jantavam pelas quatro da tarde e tomavam chá pelas sete da noite; usavam o período intermediário para descansar, organizar as coleções recolhidas e fazer anotações.

Alcide d'Orbigny foi um naturalista francês que viajou por quase toda a América do Sul entre 1826 e 1833. Em seu livro Viagem pitoresca através do Brasil, D’Orbigny (1976) ilustrou e descreveu um típico acampamento provisório na beira do rio Itapicuru, no interior do Maranhão, destacando o trabalho dos índios que o acompanhavam. Eles levantavam a cabana de pouso, nesse caso com formato inclinado e de construção mais rápida, caçavam e providenciavam a alimentação do grupo (Figura 7). Na imagem, o indígena exibe uma 


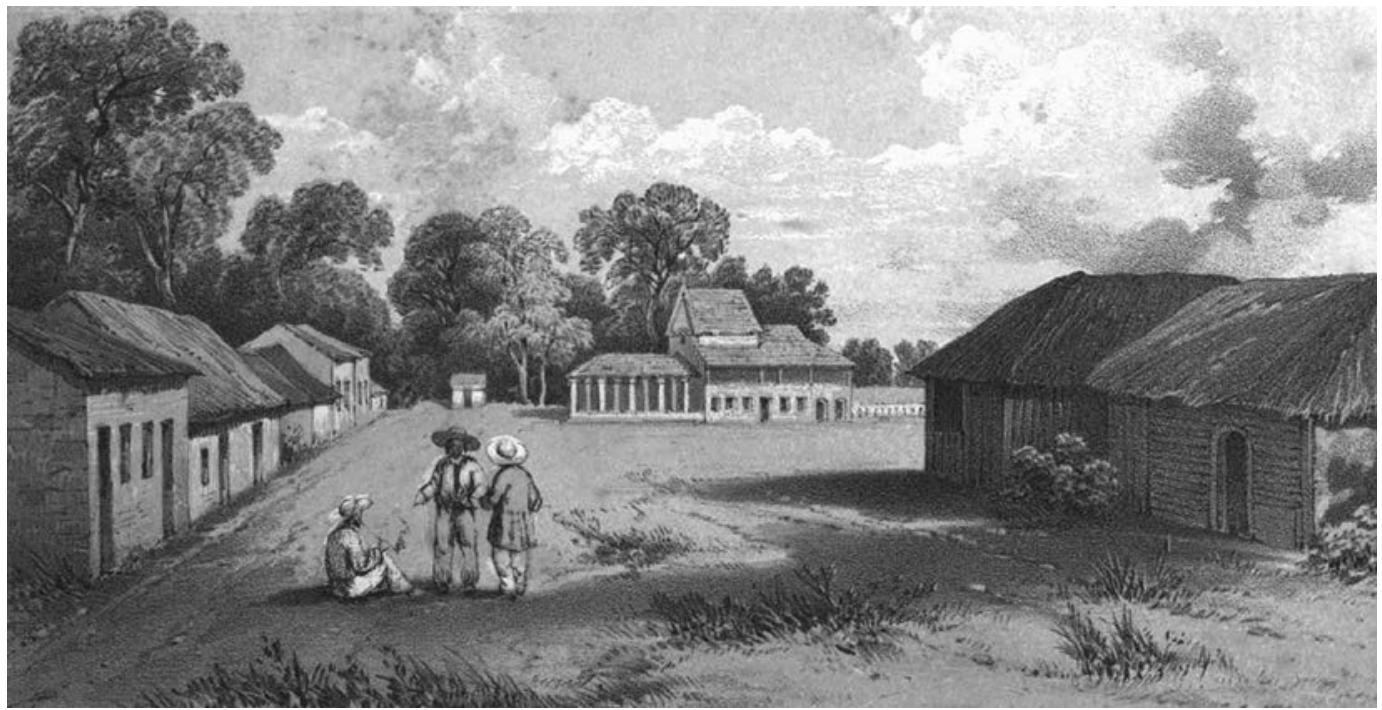

Figura 6: Alfred Wallace, Capela em Nazaré, próximo ao Pará, 1853 (Wallace, 1853)

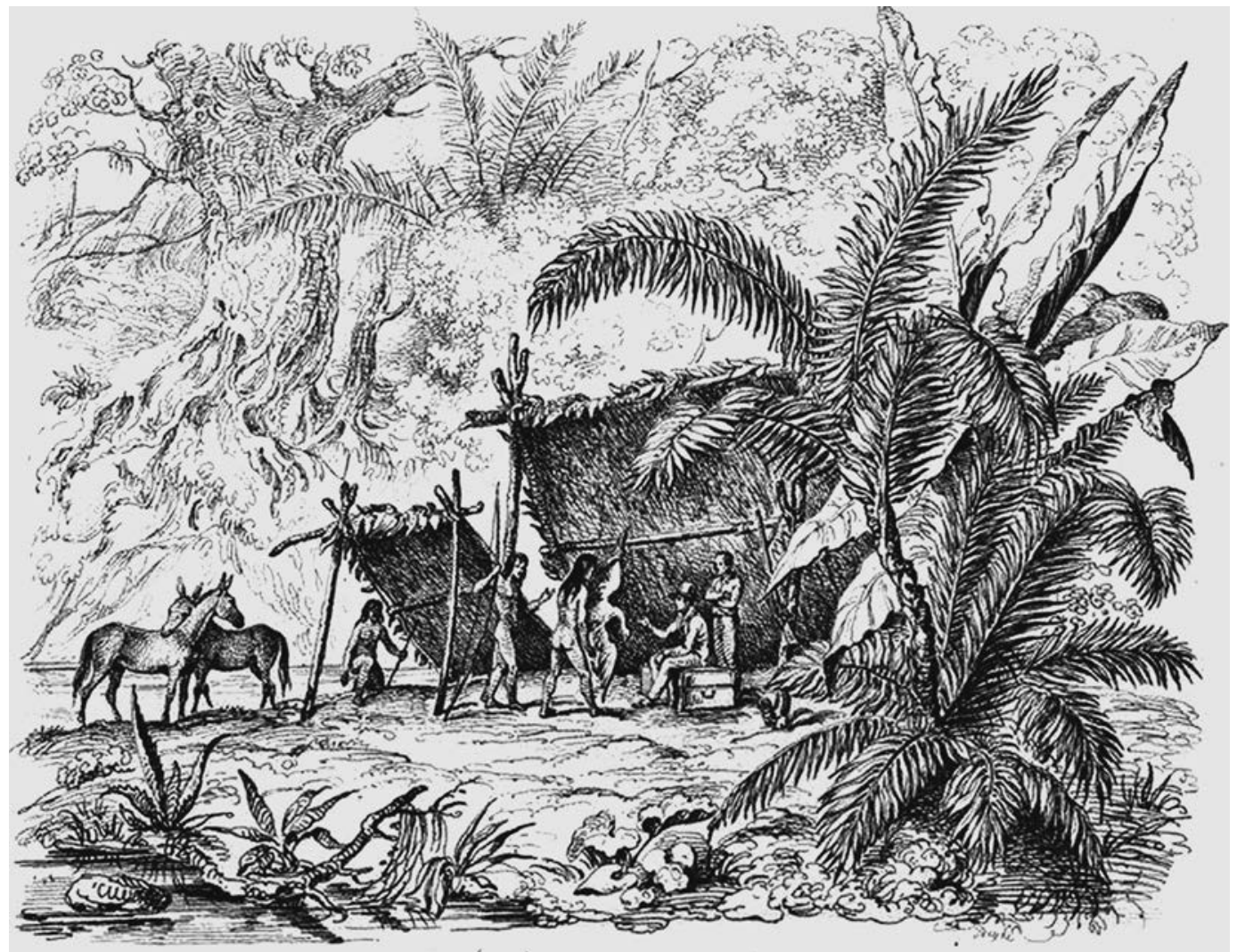

Figura 7: Alcide D'Orbigny, Acampamento numa floresta, 1841 (D'Orbigny, 1976, p.89) 
cigana ao naturalista, que aguarda sentado em cima do baú de viagem, cena observada por um português que o acompanhava na viagem.

Por diversas vezes, no decorrer da nossa viagem fluvial, tínhamos deixado, à noite, nosso barco, para acamparmos à beira do rio. No ponto que escolhíamos os índios que nos acompanhavam improvisavam uma cabana de folhas, com a ajuda de estacas e folhagens. Preparavam, em seguida, a refeição, diante de uma fogueira. Diversos deles se afastavam, para irem caçar, e nos traziam algumas grandes ciganas, aves da família dos galináceos (Opisthocomus Cristatus). Caça pouco arisca, matavam-nas com facilidade e, com boa vontade, comiam, em vez de carne-seca (D'Orbigny, 1976, p.89).

Mas não eram apenas naturalistas estrangeiros ou locais que cruzavam o país. Jean-Baptiste Debret, que permaneceu 15 anos no Brasil, desde sua chegada com a comitiva que ficou conhecida como Missão Artística Francesa, deixou um dos mais ricos legados sobre o Brasil oitocentista. O artista realizou centenas de pranchas de desenhos, nas quais situa, lado a lado, relatos daquilo que observou com ilustrações de costumes e hábitos das populações locais do Rio de Janeiro. Em uma de suas pranchas, podemos ver um acampamento típico de viajantes brasileiros que cruzavam o país no lombo de mulas, na região Sul do país.

Na Figura 8, temos a oportunidade de observar um ambiente e um modo de acampar bastante diferentes do que encontramos até agora nas imagens dos naturalistas viajantes. Partindo em viagens com objetivos principalmente comerciais, esse acampamento difere dos que encontramos anteriormente, descritos para regiões ao norte do país e com natureza bastante diversa. Uma semelhança surge, aqui, com a presença dos cães de guarda. Debret
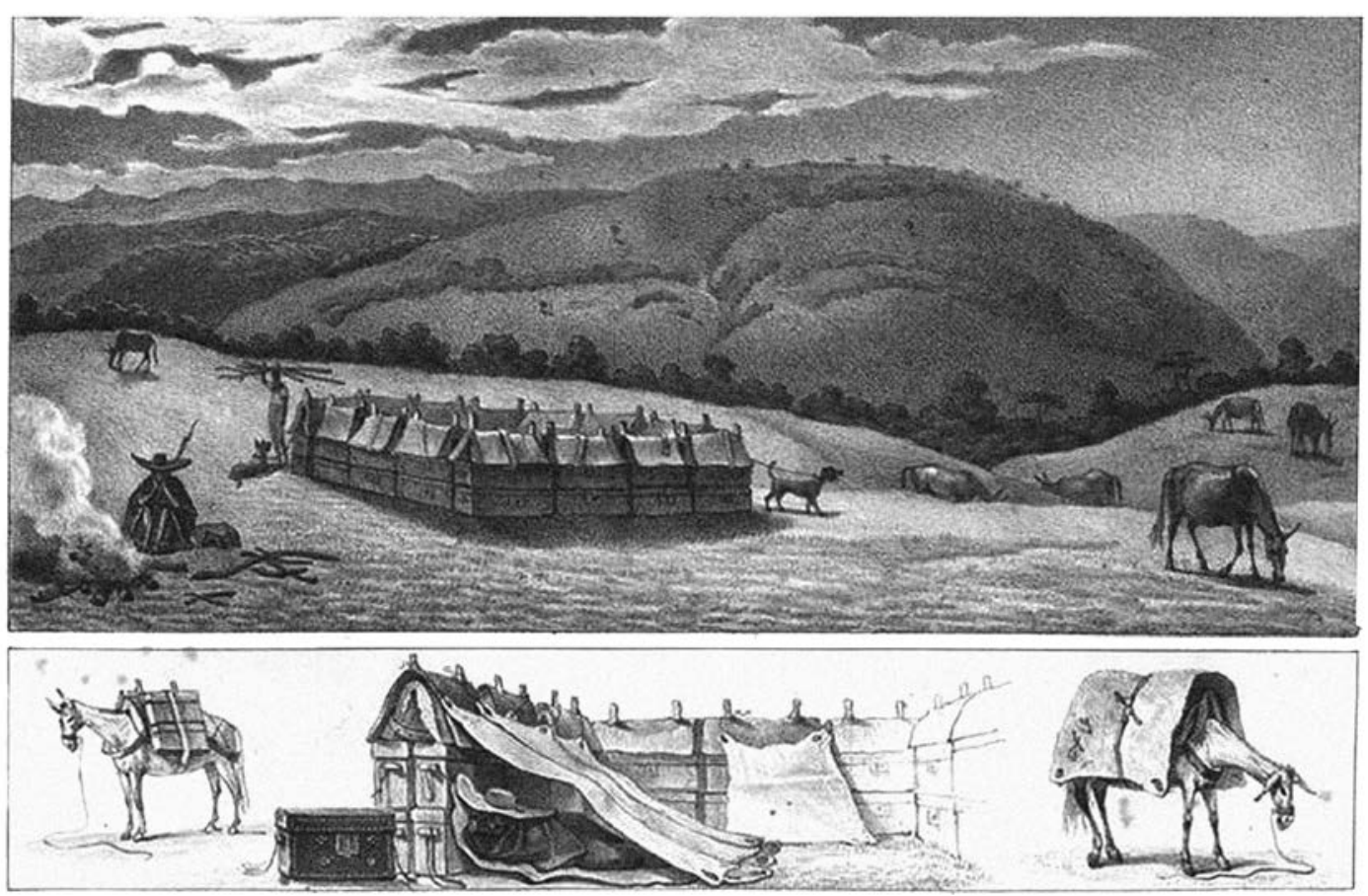

Figura 8: Jean-Baptiste Debret, Acampamento noturno dos viajantes, 1835 (Debret, 1835) 
(1835, p.85) comenta sobre uma possível escolha discriminatória da onça ao atacar um acampamento: "Quando a onça, por exemplo, ataca esses acampamentos entrincheirados, ela pratica a sua ferocidade primeiro contra os cães e, em seguida, contra os negros, antes de se atrever a saltar sobre os brancos". Para os viajantes que não podiam contar com a ajuda de oficiais de guarda ou de indígenas experientes para cuidar da vigilância de seus acampamentos, um cão era uma companhia muito útil, como verificamos na imagem de Reis Carvalho.

\section{Considerações finais}

Por meio da comparação entre as imagens analisadas, podemos perceber que, embora as regiões visitadas e os tipos de local de pouso variassem, algumas tendências eram constantes, como, por exemplo, a presença de ajudantes e a divisão das tarefas na expedição. Encarregados da preparação do acampamento, do cuidado com os animais que eram utilizados como meios de transporte, da segurança, da alimentação do grupo e da coleta de espécimes, esses auxiliares eram personagens fundamentais para o êxito das expedições, embora muitas vezes acabassem, literalmente, em segundo plano. Moreira (2002, p.42) menciona alguns dos serviços prestados por eles ou por habitantes locais aos viajantes:

o previsível apoio logístico e de infraestrutura, fornecimento de alimentos, meios de transporte e outros recursos materiais; presença como guias, carregadores, intérpretes e companhia pessoal; e auxílio nos contatos com grupos indígenas e no aprendizado de línguas nativas... identificação, localização, coleta e nomenclatura de animais e plantas; preparação e preservação de espécimes; descobertas de 'novas' espécies; análise de hábitos e usos de animais e plantas; conhecimentos geográficos, meteorológicos e de distribuição de animais e plantas; relatos antropológicos; indicação de locais mais favoráveis para pesquisa; domesticação de animais; e fabricação de instrumentos (inclusive para captura e preservação de animais).

A importância deles e a utilidade de se ter um bom relacionamento com eles é expressa por Bates em seu relato de viagem: "Eu já havia aprendido que a única maneira de alcançar os objetivos que me tinham trazido ao país era acostumar-me ao modo de vida das classes mais humildes do lugar" (Moreira, 2002, p.43).

É possível perceber, também, que em muitas dessas imagens a representação dos naturalistas segue alguns padrões. É comum encontrá-los ao centro da composição, e a posição de destaque se estende ainda para as indumentárias e as ações que realizam. Em diversos casos que analisamos, vemos os naturalistas sentados em um momento de descanso, enquanto seus ajudantes continuam a trabalhar a seu redor.

Em matéria de locais de pouso, podemos notar desde acampamentos diversos, com redes estendidas em troncos de árvores, até casas alugadas em cidades ou em seus arredores, passando por ranchos, tendas e cabanas improvisadas. No caso dos acampamentos em meio à mata, como se tratava de locais de ocupação provisória para o grupo, nos quais poderiam descansar ou passar uma noite antes de prosseguir no dia seguinte, as construções que observamos são simples, rústicas e, em muitos casos, construídas a partir do aproveitamento de material encontrado na região, e quase sempre pelos índios, escravos ou auxiliares da expedição. 
Os acampamentos mostrados nas ilustrações de Reis Carvalho e Keller-Leuzinger possivelmente foram montados para paradas breves, em intervalos para refeições. Em outros casos, para pernoite, era comum a utilização de tendas ou cabanas construídas com folhagens, como nas ilustrações de D'Orbigny e de Bates. Embora os métodos de construção e os materiais disponíveis variassem em função também da região, do seu clima e da natureza ao redor, os acampamentos dos viajantes costumavam ser constituídos por construções simples, rápidas e que podiam oferecer alguma proteção. Eram locais para descanso de homens e animais, alimentação e preparo do material recolhido.

Em termos de cenário, é possível perceber uma preferência pela ilustração de áreas com grande riqueza vegetal, que permitissem aos viajantes o duplo objetivo de registrar seus modos de viagem, assim como a flora local. Em diversas imagens, verificamos altas árvores com frondosas folhagens que cobrem quase toda a área da composição. A representação da natureza também nos passa, em alguns casos, a ideia de grandiosidade e coloca em proporção homem e natureza, transmitindo ao espectador um pouco da admiração que arrebatava os viajantes e que eles relatam em seus livros de viagem. Além da flora, também é possível observar alguns espécimes da fauna local nessas imagens, como o pássaro capturado pelo auxiliar da Comissão do Império, o jacaré próximo à rede de Bates, a cigana de D’Orbigny e os animais espalhados pela cena de Spix e Martius.

Achamos interessante ressaltar que, mesmo em posição frequentemente subalterna, a presença de auxiliares diversos - fossem eles ajudantes contratados, guias, escravos, indígenas ou outros nativos da região - era de importância central para quase todas as expedições científicas, embora tal papel seja muitas vezes diminuído ou desconsiderado em trabalhos de história da ciência. As imagens dos naturalistas ou dos artistas viajantes, mesmo traduzindo uma visão de mundo hierarquizada e socialmente condicionada, não deixam de registrar a relevância desse trabalho coletivo subjacente.

\section{NOTA}

${ }^{1}$ Nesta e nas demais citações de textos em outros idiomas, a tradução é livre.

\section{REFERÊNCIAS}

ANTUNES, Anderson Pereira.

A iconografia dos viajantes oitocentistas: um estudo comparativo das imagens realizadas no Brasil do século XIX. 2012. 132 p. Trabalho de Conclusão de Curso (Pós-graduação em Divulgação da Ciência, da Tecnologia e da Saúde) - Museu da Vida/Casa de Oswaldo Cruz/Fiocruz, Rio de Janeiro. 2012.

BATES, Henry Walter.

The naturalist on the river Amazons: a record of adventures, habits of animals, sketches of Brazilian and indian life, and aspects of nature under the Equator, during eleven years of travel. London: John Murray. 1864.
DEBRET, Jean-Baptiste.

Voyage pittoresque et historique au Brésil. t.2. Paris: Firmin Didot Frères. 1835.

D'ORBIGNY, Alcide.

Viagem pitoresca através do Brasil. Belo Horizonte: Livraria Itatiaia Editora; São Paulo: Itatiaia; Edusp. 1976.

HUMBOLDT, Alexander von.

Tableaux de la nature. Paris: Librairie de Firmin Didot Frères. Disponível em: http://gallica.bnf. fr/ark:/12148/bpt6k209770f. Acesso em: 29 maio 2015. 1850.

KELLER-LEUZINGER, Franz.

The Amazon and Madeira Rivers: sketches and descriptions from the note-book of an explorer. Philadelphia: J.B. Lippincott. 1875. 
KURY, Lorelai (Org.).

Comissão científica do Império: 1859-1861. Rio de Janeiro: Andrea Jakobsson Estúdio Editorial. 2009.

\section{KURY, Lorelai.}

Viajantes naturalistas no Brasil oitocentista: experiência, relato e imagem. História, Ciências, Saúde-Manguinhos, v.8, supl., p.863-80. 2001.

LEITE, Miriam Lifchitz Moreira.

Livros de viagem (1803-1900). Rio de Janeiro: UFRJ. 1997.

LOPES, Maria Margaret.

A Comissão Científica de Exploração: uma "expansão para dentro". In: Kury, Lorelai (Org.). Comissão científica do Império: 1859-1861. Rio de Janeiro: Andrea Jakobsson Estúdio Editorial. p.51-84. 2009.

MONTÉMONT, Albert.

Bibliothèque universelle des voyages effectués par mer ou par terre dans les diverses parties du monde depuis les premières découvertes jusqu'a nos jours. Paris: Armand-Aubrée Editeur. 1833.
MOREIRA, Ildeu de Castro.

O escravo do naturalista. Ciência hoje, v.31, n.184, p.40-48. jul. 2002.

PANOFSKY, Erwin.

Significado nas artes visuais. São Paulo:

Perspectiva. 1979.

SPIX, Johann Baptist von; MARTIUS, Karl Friedrich Philipp von.

Reise in Brasilien. München: M. Lindauer. Disponível em: http://www.biodiversitylibrary. org/item/55383\#page/1/mode/1up. Acesso em: 29 maio 2015. 1823-1831.

WALLACE, Alfred Russel.

Viagens pelos rios Amazonas e Negro. Belo Horizonte: Livraria Itatiaia Editora. 1979.

WALLACE, Alfred Russel.

A narrative of travels on the Amazon and Rio Negro, with an account of the native tribes, and observations on the climate, geology, and natural history of the Amazon valley. London: Reeve and Co. 1853. 